\title{
Bevacizumab vs ranibizumab-an appraisal of the evidence from CATT and IVAN
}

Eye (2013) 27, 289-290; doi:10.1038/eye.2013.1

The introduction of agents against vascular endothelial growth factor, such as ranibizumab and bevacizumab, has revolutionised ophthalmology. Bevacizumab has been formulated for use against cancer and is not licensed for ocular use. Nevertheless, it is administered on an off-label basis for an everexpanding range of eye conditions. Until recently, there was no Level 1 evidence on the safety and efficacy of bevacizumab when used in the eye. This changed recently when two large randomised controlled trials, IVAN and CATT, reported their results. ${ }^{1,2}$

Both trials suggested marginal superiority of ranibizumab in terms of visual acuity gain. There was little difference in retinal thickness and angiographic leakage. CATT showed that ranibizumab was associated with more geographic atrophy at 2 years. There were no differences in endophthalmitis rates or mortality. In IVAN, there were more arteriothrombotic events and heart failure with ranibizumab. Other adverse events were collected using the MedDRA system class. In CATT, these were more frequent with bevacizumab than ranibizumab, $24 \%$ vs $19 \%$ at 1 year, and $40 \%$ vs $32 \%$ at 2 years. These adverse events were distributed across a wide range of organ class, and many seemed unrelated to VEGF suppression. Adverse events included infections, palpitations, and accidents.

However, the biggest imbalance was with gastrointestinal disorders, 11 with ranibizumab and 28 with bevacizumab. Gastrointestinal (GI) disorders included hernia, nausea, vomiting, and haemorrhage (two ranibizumab, seven bevacizumab-data presented at ARVO 2012). Intriguingly, these side effects did not appear to be dose-related, but quite the opposite. Patients
FG Ahfat and FH Zaidi

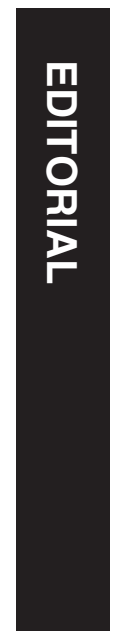

who received more injections suffered fewer adverse events. The CATT investigators gave three possible explanations for the excess of adverse events with bevacizumab: a true difference in risk, allocation bias, or chance. What evidence is there for each of these?

A meta-analysis of 16 randomised control trials showed that in cancer patients bevacizumab at weekly doses of up to $400 \mathrm{mg}$ did increase the risk of GI bleeds. ${ }^{3}$ However, the risk was increased only when bevacizumab was combined with taxanes and platinum agents.

There was no increased risk if bevacizumab was used with agents like 5-fluorouracil. Arguably, the most important finding in CATT and IVAN was on hypertension. Hypertension is probably the best indirect marker of tissue VEGF suppression. Various studies have demonstrated the ability of ocular doses of bevacizumab (1.25 mg monthly) in inhibiting plasma or serum VEGF. ${ }^{1,4,5}$ However, to suppress VEGF at tissue level, as in cancer, much higher doses of bevacizumab are required, up to $400 \mathrm{mg}$ weekly. At these doses, a renal thrombotic microangiopathy develops, leading to hypertension. ${ }^{6,7}$ The absence of hypertension in CATT and IVAN suggests that systemic tissue VEGF suppression with bevacizumab is minimal at ocular doses.

Was there any evidence of allocation bias? The baseline characteristics in CATT show that almost twice as many patients on bevacizumab than on ranibizumab had had a previous TIA. ${ }^{8}$ These patients were probably more likely to have been on an antiplatelet drug and hence more prone to suffer a GI haemorrhage. It may also be relevant that the bevacizumab patients were older (80.1 vs 79.2 years in the monthly arm, and 79.3 vs 78.4 years in the 'prn' arms), and so may have been more likely to suffer ill health. It is important to note that during the course of the CATT study, around three-quarters
Eye, Ear and Mouth Unit, Maidstone and Tunbridge Wells NHS Trust, Maidstone, UK

Correspondence: FG Ahfat, Eye, Ear and Mouth Unit, Maidstone and Tunbridge Wells NHS Trust, Hermitage Lane, Maidstone, Kent ME16 9QQ, UK.

Tel: + 44 (0)1622 226289 ;

Fax: + 44 (0)1622 226298

E-mail: ahfat99@

hotmail.com

This work was previously presented, in part, at the Royal College of Ophthalmologists Annual Congress, Liverpool, May 2012. 
of patients became unmasked to the drug and were able to deduce the treatment arm they were in from their insurance documents. ${ }^{2}$ CATT required documentation of every conceivable adverse event suffered by patients along the MedDRA system, ranging from strokes to heart attacks and from hernia to toothache. ${ }^{8}$ It is plausible this unmasking may have introduced an element of reporting bias. Patients allocated to 'the cheap drug' on an 'infrequent basis' may have been more inclined to self-report 'adverse events' than patients allocated to 'the expensive drug' on a 'monthly regimen'. Such 'adverse events' would be very common in the age group under study, and an association does not imply cause and effect.

What role does chance have in clinical trials? Clinicians often fail to appreciate the influence of chance in clinical trials, the random nature of statistics, and the significance of spurious results or Type 1 errors. In 1988, the ISIS-2 study looked at 17187 patients who had suffered myocardial infarctions, and showed that aspirin significantly decreased mortality $(P<0.00001)$. Re-analysis of the data according to astrological signs revealed that patients born under Gemini and Libra had a slightly higher mortality. ${ }^{9,10}$ The DICE study showed an increased mortality from throwing a red dice after strokes. ${ }^{11}$ The Optic Neuritis Treatment Trial showed that after an attack of optic neuritis, intravenous corticosteroids decreased recurrence rates, but oral corticosteroids had the opposite effect $(P=0.002) .{ }^{12}$ This finding is now widely regarded as spurious. Like IVAN, both the SAILOR and SUSTAIN studies suggested an increased risk of stroke with ranibizumab. ${ }^{13,14}$ A meta-analysis of the MARINA, ANCHOR, and FOCUS studies found higher rates of strokes with ranibizumab. ${ }^{15}$ Closer examination of the data also suggested that ranibizumab protects against myocardial infarction. Curiously, a third of the data showed an increased risk of strokes or myocardial infarction, a third showed a decreased risk, and a third showed no difference. The rate of these events varied widely, even amongst controls, suggesting Type 1 error.

It has been argued that CATT and IVAN were not powered to look at safety, that the sample sizes were too small and that more studies are needed. More studies are surely welcome, but one needs to appreciate that the laws of statistics dictate that some of these studies will throw up spurious results, whereas others, however well-designed and conducted, will be subject to some form of bias. Conducting more studies does not reduce the chances of Type 1 errors, but quite the opposite. This phenomenon has been seen in the debate over mobile telephones, where several thousand studies have failed to settle the argument as to whether mobile telephones cause cancer. Studies on macular degeneration are no exception to this phenomenon. The devil indeed lies in the correct interpretation of the statistics.

\section{Conflict of interest}

FGA is a principal investigator for the IVAN trial. FHZ declares no conflict of interest.

\section{References}

1 The IVAN Study Investigators, Chakravarthy U, Harding SP, Rogers CA, Downes SM, Lotery AJ et al. Ranibizumab versus bevacizumab to treat neovascular age-related macular degeneration: one-year findings from the IVAN randomized trial. Ophthalmology 2012; 119: 1399-1411.

2 Comparison of Age-related Macular Degeneration Treatments Trials (CATT) Research Group. Ranibizumab and Bevacizumab for treatment of neovascular age-related macular degeneration two-year results. Ophthalmology 2012; 119: 1388-1398.

3 Ranpura V, Hapani S, Wu S. Treatment-related mortality with bevacizumab in cancer patients: a meta-analysis. JAMA 2011; 305: 487-494.

4 Matsuyama K, Ogata N, Matsuoka M, Wada M, Takahashi K, Nishimura T. Plasma levels of vascular endothelial growth factor and pigment epithelium-derived factor before and after intravitreal injection of bevacizumab. $\mathrm{Br} \mathrm{J}$ Ophthalmol 2010; 94: 1215-1218.

5 Ma Y, Zhang Y, Zhao T, Jiang YR. Vascular endothelial growth factor in plasma and vitreous fluid of patients with proliferative diabetic retinopathy patients after intravitreal injection of bevacizumab. Am J Ophthalmol 2012; 153: 307-313.

6 Zhu X, Wu S, Dahut WL, Parikh CR. Risks of proteinuria and hypertension with bevacizumab, an antibody against vascular endothelial growth factor: systematic review and meta-analysis. Am J Kidney Dis 2007; 49: 186-193.

7 Levy A, Albiges-Sauvin L, Massard C, Izzedine H, Edhery $\mathrm{S}$, Bahleda R et al. Reappraisal of treatment-induced renal dysfunction in patients receiving antiangiogenic agents in phase 1 trials. Invest New Drugs 2012; 30: 1116-1120.

8 The CATT Research Group. Ranibizumab and bevacizumab for neovascular age-related macular degeneration. $N$ Engl J Med 2011; 364: 1897-1908.

9 ISIS-2 (Second International Study of Infarct Survival) Collaborative Group. Randomised trial of intravenous streptokinase, oral aspirin, both, or neither among 17,187 cases of suspected acute myocardial infarction. Lancet 1988; 2: 349-360.

10 Oxman AD. Subgroup analyses: the devil is in the interpretation. BMJ 2012; 344: e2022.

11 Counsell CE, Clarke MJ, Slattery J, Sandercock PA. The miracle of DICE therapy for acute stroke: fact or fictional product of subgroup analysis? BMJ 1994; 309: 1677-1681.

12 Beck RW, Cleary PA, Trobe JD, Kaufman DI, Kupersmith MJ, Paty DW et al. The effect of corticosteroids for acute optic neuritis on the subsequent development of multiple sclerosis. N Engl J Med 1993; 329: 1764-1769.

13 Boyer DS, Heier JS, Brown DM, Francom SF, Ianchulev T, Rubio RG. A phase IIIb study to evaluate the safety of ranibizumab in subjects with neovascular age-related macular degeneration. Ophthalmology 2009; 116: 1731-1739.

14 Holz FG, Amoaku W, Donate J, Guymer RH, Kellner U, Schlingemann RO et al. Safety and efficacy of a flexible dosing regimen of ranibizumab in neovascular age-related macular degeneration: the SUSTAIN Study. Ophthalmology 2011; 118: 663-671.

15 Ueta T, Yanagi Y, Tamaki Y, Yamaguchi T. Cerebrovascular accidents in ranibizumab. Ophthalmology 2009; 116: 362. 